\title{
The Sunk Cost and the Real Option Pricing Model
}

\author{
Songsong Li $\mathbb{D}$, Yinglong Zhang $\mathbb{D}$, and Xuefeng Wang \\ School of Management, Harbin Institute of Technology, 92 West Dazhi Street, Nangang District, Harbin 150001, China \\ Correspondence should be addressed to Yinglong Zhang; alvinz1023@163.com
}

Received 3 August 2021; Accepted 15 September 2021; Published 30 September 2021

Academic Editor: Wei Zhang

Copyright $\odot 2021$ Songsong Li et al. This is an open access article distributed under the Creative Commons Attribution License, which permits unrestricted use, distribution, and reproduction in any medium, provided the original work is properly cited.

\begin{abstract}
Although the academic literature on real options has grown enormously over the past three decades, hitherto an accurate real option pricing model has not been developed for investment decision analyses. In this paper, we propose a real option pricing model based on sunk cost characteristics, which can estimate the value of real options more accurately. First, we explore the distinctive features that distinguish real options from financial options. The study shows that the distinguishing feature of the real options is the sunk cost, which does not exist in the financial options. Based on the sunk cost characteristic of real options, we find that the exercise conditions of real and financial options are different. Second, we introduce the sunk cost into the intrinsic value function of real options and establish a new real option pricing model. Finally, this paper also discusses the properties of the intrinsic value function and pricing model of real options. We find that the application of the Black-Scholes option pricing model will overestimate the value of real options.
\end{abstract}

\section{Introduction}

The concept of real options was introduced by Myers [1] who was the first to recognize the potential value of applying the financial options theory to real investment projects and presented a formal real options model. The real option allows the investor to lock losses at a certain cost in advance when facing future uncertainties while retaining the chance to gain future rewards at the same time. In contrast to investment decision analysis based on the traditional discounted free cash flow method of asset valuation, which bounds the investor to a fixed setting, the real options provide future flexibility in investment decisions. Application of real option in investment decision analysis permits the decision-maker to effectively deal with the uncertainties associated with the investment. Moreover, in any investment decisions in real assets such as investment in natural resource exploration, acquisitions of enterprises, or investment in technology development, real options give the investor the options to "defer, abandon, shutdown and restart, expand, contract, and switch" ([2]; p.2). This implies that the real options have two components: the intrinsic value (the net present value) and the time value. Ample evidence that real options play an important role in initiating or terminating investment by enterprises [3-5] has led to advancement of the theory of real options in the last several decades [6-9]. In addition, many papers and books on the application of real options have been published in a wide range of subjects including evaluating the value of $R \& D$ projects in the pharmaceutical enterprises [10-12] and the value of public policies in encouraging private investment [13], in land use [14], in financial analysis [15], in assessing the value of agricultural projects [16], and in corporate mergers and acquisitions ([17, 18]; chapter 9).

The commonly used real option pricing methods include risk-adjusted net present value method (This method requires a knowledge of the value of the probability of cash flows and the cost of capital. In practice, however, values of these parameters are not known.), binary tree pricing method, and Black-Scholes option pricing model (hereinafter referred to as B-S model), among which the B-S model is the most popular. For example, Zmeškal [19] proposed a generalized hybrid fuzzy-stochastic binomial American real option model based on fuzzy number theory and decomposition principle. Heng et al. [20] constructed a fuzzy Black-Scholes option model to evaluate land prices by combining trapezoidal fuzzy number and Carlsson-Fuller model. Zubrii et al. [21] used genetic algorithms and 
evolutionary algorithms to analyze and predict real option prices. In the real options literature, scholars tend to use the method of real options in project evaluation analysis; however, many practitioners apply the standard B-S model to assess the value of the asset without considering the sunk cost in their decision analysis. The sunk cost of real options refers to the initial capital outlays associated with starting an investment project. Examples of sunk costs include expenses related to due diligence and company valuation in mergers and acquisitions or the initial expenditures in obtaining a concession in resource development. Specifically, in petroleum development projects, the initial investment in seismic exploration, early experimental costs, and investigation and assessment costs are sunk costs. When investment decisions do not involve the initial sunk costs but companies incur losses after completion of the project, they abandon them to avoid additional losses. In contrast, when investment decisions involve considerable uncertainty and sunk costs in deciding whether to invest, it is rational for the investor to persist and incur some losses in the hope of earning the expected profits [6]. Under the latter circumstances, the option of exercising future managerial discretion is most valuable [22]. If circumstances do improve, enterprises that decided to exit are likely to regret the decision, since they must incur the sunk cost again to reenter the industry. Investment decision-makers often neglect including the initial outlay in the real option exercise price and directly use B-S model to calculate the asset value after carefully selecting the values of the five parameters (current underlying asset value of the option, exercise price, the volatility rate of the asset price, the expiration date of the option, and risk-free interest rate). However, it is well known that determining the accurate price of the real option with the use of the financial option pricing model requires the consistency of the timing of the execution and abandonment of the option as well as a knowledge of the return characteristics of the asset. In case of inconsistencies, simply comparing the upfront investment cost of real options with the strike price of the financial options would pose serious issues, and simply copying the pricing model of financial options in the real option pricing may cause major investment decision-making errors $[23,24]$.

In this paper, we discuss the essential difference between real options and financial options and modify the financial option pricing model to account for the sunk cost. We find the difference mainly lies in the presence of the sunk cost in the exercise price of the real options, a quantity that does not enter in the strike price of the financial options. Therefore, it is necessary to take the sunk cost feature of the initial investment into account when evaluating the value of real options by determining the conditions for executing or abandoning the real options accordingly. Moreover, using the B-S model, we derive the intrinsic value function of real options and formulate a new real option pricing model. These results not only specifically contribute to the theory of real options and to the broader literature on investment decision-making but also have important implications for investment professionals. The main contributions of this paper lie in the following aspects:
(1) By analyzing the essential differences between real options and financial options, we discover the existence of the sunk cost feature in real options, which provides a new perspective to improve the construction of real option pricing models.

(2) Based on the sunk cost feature, we propose a novel pricing model for real options. For investment decision-makers and policy-makers, our model can estimate the value of real options more accurately and may be more informative.

The paper is organized as follows. In Section 2, we discuss the characteristics of real options, that is, the essential differences between real options and financial options. Section 3 discusses the execution conditions of real options. We give the conditions for exercising or giving up real options and explain the differences in executing conditions between the two options. The mathematical expression of intrinsic value function of real options based on the sunk cost is derived in Section 4. In Section 5, we establish a new real option pricing model using the intrinsic value of real options based on the sunk cost and discuss the circumstances when the salvage value of exercise price is taken for extreme value. Section 6 presents the analysis of the pricing model and gives some characteristics of the model. Conclusion and discussion are presented in Section 7.

\section{Characteristics of Real Options}

2.1. Exercise Price of Real Options including Sunk Costs. In the financial options analysis, the strike price is also known as the exercise price. In this paper, we distinguish financial options from real options by calling the strike price in the real options the exercise price. The strike price of a financial option is the price of the underlying asset stipulated in the contract. The exercise price in real options is the advance capital outlays by the investor to obtain the right to begin work on a project or the right to enter an industry. In the existing literature, the concept of the preinvestment value of real option projects is considered similar to the concept of the strike price of financial options but does not account for the sunk cost contained in real options. Our research results suggest that these two concepts are not completely equivalent. In general, a large proportion of the upfront investment cost in a project is unrecoverable, which is a sunk cost. When the external circumstances do not warrant continuing investment in the project after the initial outlay, by abandoning the project, the investor cannot fully recover the initial investment cost. In contrast to the real option, the sunk cost of the initial investment is not present in the financial options.

The sunk cost feature of early investment is mainly determined by the two following factors: research and experimental expenses, as well as the specificity of fixed assets formed by the upfront investment. For example, take petroleum development projects. Upfront investment costs such as seismic exploration, the early experimental, investigation, and assessment have a typical sunk cost feature. However, the special roads and oil pipelines for the future 
transportation of oil are typical specific assets that are uniquely constructed for the ongoing investment project. Once a specific asset in a certain field is formed, it will be locked in a particular form. If it is used for other purposes or sold off, its value greatly depreciates. Special roads and pipelines built to transport oil are nearly useless for other transportation purposes. If an unexpected plunge in oil prices causes the value of the fixed asset portion of the upfront investment to plummet and investors believe that this decline in the market price will persist over the long run, then, with high probability, investors will abandon the oil development project in the region. The depreciated part of fixed assets is equivalent to sunk costs. The nonfixed assets invested in the early stage of project development are generally sunk costs, which are incurred by the investors.

\subsection{Intrinsic Value of the Real Options Could Be Negative.} For the European financial call option, the intrinsic value of the option (the payoff) is $f(S)=\max \left(S-X_{e}, 0\right)$, where $S$ is the current market price of the underlying financial assets and $X_{e}$ is the strike price. Accordingly, the intrinsic value of financial options is always nonnegative. In applying the financial option pricing principle to the field of real investment, it is implicitly assumed that the real option and financial call option are similar; hence, the B-S model is used. The direct use of the B-S model indicates the admission of the following fact: When the total outlay of the investment project, let us call it the market price $S$ of the investment project, is lower than the exercise price $X_{e}$ of the option, the option is abandoned and the owner of the option suffers no loss. Consider that the exercise price of the real options is the initial investment in, for example, manpower, material, and financial resources, all of which contain the sunk cost, compared to a fixed price that is stipulated in a financial option contract, which contains no sunk cost. Therefore, for the real options, involving sunk costs, abandoning the options means accepting the sunk cost in upfront investment.

Real options could have a negative value. For example, an $R \& D$ project with a huge investment cannot guarantee immediate or even long-run economic benefits. In the R\&D projects, the exercise price of real options $X_{e}$ is large because the capital outlays of $\mathrm{R} \& \mathrm{D}$ projects are typically very high. Moreover, compared to the exercise price, the revenue stream of the successful project might be small. This situation shows that the enterprise is willing to incur large costs for obtaining technical capabilities only to avoid being surpassed by the competitors. In such cases, the investment project must have a negative option value. The economic significance of the negative value of real options is the cost of acquiring technology. If real options are evaluated by using the net present value method, real options with negative values might occur. However, a negative real option value contradicts the requirement of nonnegative option price according to the B-S model. The nonnegativity of the financial option is due to the fact that the option price is a product of two nonnegative terms: the intrinsic value function and the probability density function.
2.3. Both the Formation of Real Options and the Acquisition of Future Returns Require a Production Process. Financial options have a trading market. The return of financial options is realized at an instance by exercising the options. The strike price of the financial options is a stipulated value at the time the option is written. The real option is created at the time of the investor's upfront investment. The underlying asset can enter the production process only after the completion of the investment project. Moreover, the project value is determined only after the start of the production process. Accordingly, for real options, the formation of exercise price needs an investment and construction process, and the realization of project value also needs a production process, which is different from that of financial options. For financial options, returns are obtained if they are exercised. This is not the case for real options. The returns on the investment are determined after the gestation and beginning of production. This introduces additional uncertainty into the analysis. For example, one cannot be certain about future price stability. To overcome the problem of future price variability, one may have to use the average of past prices to substitute the future overall price, which introduces additional uncertainty into the analysis.

\section{Exercise Conditions of Real Options}

As discussed above, unlike the financial options, the underlying asset for writing real options involves physical capital such as natural resources, plants and equipment, enterprises, or intellectual property rights such as technology. There are many characteristics of physical assets that are different from those of financial assets. The corresponding relationship between variables that determine the value of real options and financial options is shown in Table 1.

As is seen in Table 1, the only difference between the real and financial options is the exercise price or the strike price. In real options, the exercise price is determined by the initial outlay, part of which is the sunk cost. However, in the financial option, the exercise price is a price that is stipulated in the option contract and agreed upon by the parties in the contract.

For real options, to exercise or abandon an option is determined by the returns due to the sunk cost in the exercise price. If the return on exercising the option (although the value may be negative) is greater than the return of abandoning the option (avoiding additional cost by exercising the contract), it is rational to exercise the option. For example, in a real options project, suppose the upfront investment in a project is 1 billion dollars, of which 600 million dollars is the sunk cost. Also, suppose the return of exercising the option is 800 million dollars, which makes the loss equal to 200 million dollars (800 million dollars minus 1 billion dollars), if calculated according to the current market price. If the option is abandoned, a salvage value of 400 million dollars can be obtained, and the loss is 600 million dollars (400 million dollars minus 1 billion dollars). The investors will surely exercise the options. In this example, the investor by exercising the real option has minimized the loss. 
TABLE 1: Variables between real and financial options in the B-S model.

\begin{tabular}{lcc}
\hline Parameters & Real options & Financial options \\
\hline$S$ & The current market price of the underlying real assets & The current market price of the underlying financial assets \\
$X_{e}$ & Exercise price determined by the initial investment cost & The strike price in an option contract \\
$T$ & The time to expiration of the option & The time to expiration of the option \\
$\sigma$ & The volatility of project value & The volatility of the financial asset price \\
$r$ & Risk-free interest rate & Risk-free interest rate
\end{tabular}

For real options, the conditions for exercising or abandoning the option are not apparent. We use $X_{\text {res }}$ to represent the salvage value of the exercise price, which is the asset value realized if the options are sold at the end of the upfront investment period. $X_{\text {sunk }}$ represents the sunk cost after upfront investment, which is a part of the exercise price. Firstly, if the price of asset $S$ is higher than the upfront investment cost $X_{e}$, that is, $S-X_{e}>0$ (option is in-the-money), then exercising the option is profitable. The intrinsic value of the option is the price of asset $S$ (the already realized present discounted value of cash flow) minus the exercise price $X_{e}$ (upfront investment), and the condition for exercising the option is $S>X_{e}$. Secondly, suppose the market price $S$ is lower than the exercise price $X_{e}$, but the market price $S$ can offset part of the sunk cost; then $X_{\text {res }}<S<X_{e}$ holds. In this case, exercising the options project is unprofitable; that is, the present discounted value $S$ of cash flow realized by exercising the options project is less than the upfront investment $X_{e}$. However, abandoning the project implies the loss of the sunk cost in upfront investment and the investor can only obtain the salvage value $X_{\text {res }}$. Accordingly, the return of abandoning the option is $-\left(X_{e}-X_{\text {res }}\right)=-X_{\text {sunk }}$. If exercising options, the intrinsic value of option $S-X_{e}$ is negative, but $S-X_{e}>-\left(X_{e}-X_{\text {res }}\right)$, which indicates that exercising the option is better than abandoning the option. From the last inequality, we observe that when $X_{\text {res }}<S<X_{e}$ exercising the option will bring losses, even though it can partially offset the sunk cost in upfront investment. Therefore, it is rational to exercise the option and the condition for exercising options is $S>X_{\text {res }}$. Finally, suppose $S<X_{\text {res }}$; then the return of abandoning the option is $-\left(X_{e}-X_{\text {res }}\right)$. If the intrinsic value (the net present value) of the option is $S-X_{e}<0$, but $S-X_{e}<-\left(X_{e}-X_{\text {res }}\right)$, then abandoning the option is better than exercising it. When the market price $S<X_{e}$ and $S<X_{\text {res }}$, exercising the option will bring greater losses. It is rational to abandon the option, and the condition for abandoning the option is $S<X_{\text {res }}$.

In short, for real options, the option will be exercised if the market price $S$ is higher than $X_{\text {res }}$; otherwise, the option will be abandoned. When $X_{\text {res }}<X_{e}$, the conditions for exercising or abandoning real options are different from those of financial options. The analysis of the exercise conditions of real options provides an important basis for constructing the intrinsic value function of real options.

\section{Intrinsic Value Function of Real Options}

The derivation of the intrinsic value function of real options based on sunk costs is an indispensable step in building a real option pricing model. To derive the intrinsic value function of real options, we first study the intrinsic value function of financial options. The intrinsic value of a financial option is the value of the option contract itself, which is also the return that the buyer of the option can gain if the option is exercised immediately. If $f(S)$ represents intrinsic value (the net present value) of the option, then the intrinsic value function of the call option and the put option can be expressed by the two following equations, respectively:

$$
\begin{aligned}
& f(S)=\left\{\begin{array}{ll}
0, & 0 \leq S<X_{e}, \\
S-X_{e}, & S \geq X_{e},
\end{array},\right. \\
& f(S)= \begin{cases}X_{e}-S, & S<X_{e}, \\
0, & S \geq X_{e} .\end{cases}
\end{aligned}
$$

The form of $f(S)$ is a polyline, and the turning point is at $S=X_{e}$, and $f(S) \geq 0$. Regardless of options expenses, the value of financial options $f(S)$ is always greater than or equal to 0 . That is because the options are abandoned in unfavorable circumstances and exercised in favorable circumstances and the probability of the occurrence of a favorable situation is greater than 0 , because we assume $S$ is a stochastic process and follows the geometric Brownian motion, whose distribution interval is 0 to infinity. For financial options, the typical underlying asset is stock, and the stock price $S \geq 0$. The prices of foreign currencies in the foreign exchange market and the interest rates in deposit and loan markets are nonnegative. In the geometric Brownian motion model, it is assumed that the underlying asset price $S$ follows a logarithmic normal distribution, provided that the market price $S$ is positive (see, e.g., [8]).

For real options, there may be a situation where the market price $S$ of the underlying asset is negative. The situation occurs when the market price of the product is lower than the average cost of production, which would result in negative cash flow if the output is produced. Projects that can only generate negative cash flow should be abandoned because the production would increase losses. In real investment, if an option is abandoned, the salvage value can be obtained because

$$
X_{e}=X_{\text {res }}+X_{\text {sunk }}
$$

There are two extreme cases. First, $X_{\text {res }}=0$, which implies the upfront investment is all sunk cost, and the upfront investment does not form valuable fixed assets or valuable intangible assets. Second, $X_{\text {res }}=X_{e}$, which shows that there is no sunk cost in the upfront investment, and the salvage value of the upfront investment equals the total investment. If the investor decides to abandon the project before the start of the production process, that is, 


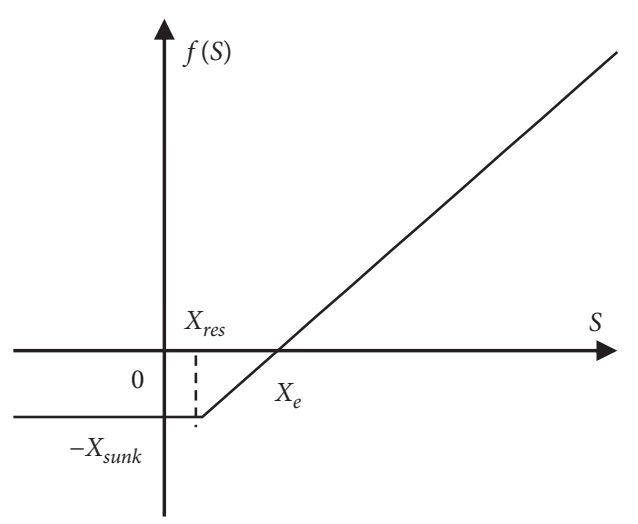

(a)

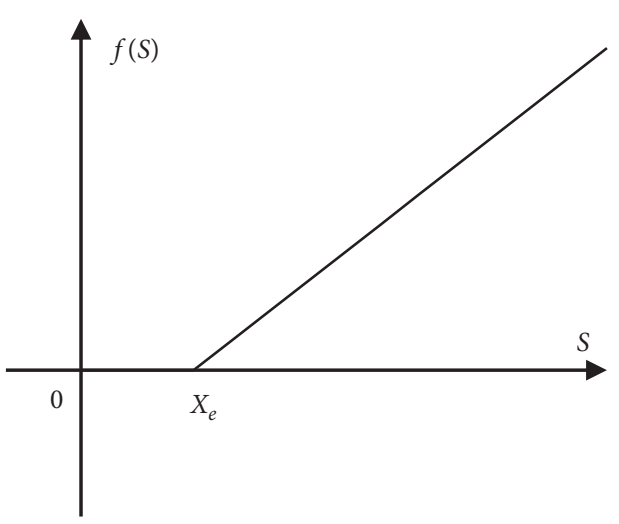

(b)

Figure 1: Intrinsic value function. (a) Real options; (b) financial call options.

abandoning the option, at this time, the fixed assets formed in the upfront investment are new, and the salvage value is $X_{\text {res. }}$. If the investor decides to exercise the option, after the production process is completed, the fixed assets formed in the upfront investment have been used for some time and the salvage value at the time of abandoning the option is less than $X_{\text {res }}$.

Considering the sunk cost in upfront investment as well as the discussion on the exercising conditions of real options, we know that the condition for abandoning the real option should be $S<X_{\text {res }}$. Furthermore, at the time of abandoning the option, the loss is $X_{\text {sunk }}=X_{e}-X_{\text {res}}$, and the corresponding return is $-X_{\text {sunk }}=-\left(X_{e}-X_{\text {res }}\right)$. The condition for exercising an option is $S \geq X_{\text {res }}$, which implies the return is $S-X_{e}$. When $X_{\text {res }} \leq S<X_{e}$, the return is negative. When $S \geq X_{e}$, the return is positive. Accordingly, the intrinsic value function of real options is shown as follows:

$$
f(S)= \begin{cases}-\left(X_{e}-X_{\text {res }}\right), & S<X_{\text {res }}, \\ S-X_{e}, & S \geq X_{\text {res }} .\end{cases}
$$

So long as the upfront investment includes sunk costs, that is, $X_{\text {sunk }}>0$, the inequality $X_{\text {res }}<X_{e}$ holds. Under such condition, the intrinsic value function of real options is different from that of financial call options, because the intrinsic value function of real options is negative when $S<X_{e}$. When $X_{\text {res }}=0$, the intrinsic value function of real options is

$$
f(S)= \begin{cases}-X_{e}, & S<0, \\ S-X_{e}, & S \geq 0 .\end{cases}
$$

When $X_{\text {res }}=X_{e}$, the intrinsic value function of real options is

$$
f(S)= \begin{cases}0, & S<X_{e} \\ S-X_{e}, & S \geq X_{e}\end{cases}
$$

Only when $X_{\text {res }}=X_{e}$ are the intrinsic value functions of real option and the financial call options identical and under that condition $X_{\text {sunk }}=0$. But, in real investment, it is rare that there is no sunk cost in the upfront investment of a project. The sunk cost accounts for a large proportion of upfront investment in most real investment projects. The graph of the intrinsic value function of the real options and the financial call options is shown in Figure 1.

As can be seen from the graph, the intrinsic value of a financial call option is nonnegative, while the intrinsic value of a real option is negative at $S<X_{e}$. The turning point of the real option's intrinsic value function is at $S=X_{\text {res }}$. For the most part, real investment projects, $X_{\text {res }}<X_{e}$, the intrinsic value function of the real option is significantly different from that of the financial call option. Next, we will derive the real option pricing model based on the intrinsic value function of real options obtained above.

\section{A Real Option Pricing Model Based on the Sunk Cost}

5.1. Black-Scholes Differential Equation and European Call Option Pricing Model. The B-S model is the most important pricing tool for financial options. Take the stock price for example. Assume the stock price $S(t)$ obeys the geometric Brownian motion; then,

$$
\frac{\mathrm{d} S(t)}{S(t)}=\mu \mathrm{d} t+\sigma \mathrm{d} W(t) .
$$

In equation (7), $W(t)$ is the standard Brownian motion, and $\mu$ and $\sigma$ are positive constant numbers. Under the assumption that the stock price follows the geometric Brownian motion, according to the no-arbitrage principle and the Ito theorem in random process theory, Black and Scholes derive the following famous partial differential equation that the stock option price $V(S, t)$ satisfies

$$
\frac{\partial V}{\partial t}+r S\left(\frac{\partial V}{\partial S}\right)+\left(\frac{1}{2}\right) \sigma^{2} S^{2}\left(\frac{\partial^{2} V}{\partial S^{2}}\right)=r V .
$$

In equation (8), $V$ represents the price of a stock-based option, $t$ represents the time, $r$ represents the risk-free interest rate, $\sigma$ represents the volatility of the stock price, and $S$ represents the asset price.

The first term on the left side of equation (8) measures the investor's long position over time. The second term on the left side of the equation shows the variation of the long 
position with respect to changes in the price of the underlying asset for the option. Finally, the term $\left(\partial^{2} V / \partial S^{2}\right)$ measures the rate of change in the variation of the long position with respect to the variation of the price of the underlying asset of the option.

Black-Scholes' integral expression of the solution of the partial differential equation is

$$
V(S, t)=\left(\frac{\exp (-r(T-t))}{\sqrt{2 \pi}}\right) \int_{-\infty}^{+\infty} f\left(S \exp \left(\sigma \sqrt{T-t} z+(T-t)\left(\frac{r-\sigma^{2}}{2}\right)\right)\right) \exp \left(\frac{-z^{2}}{2}\right) \mathrm{d} z
$$

In equation (9), $T$ is the time to expiration of the options. $f\left(S \exp \left(\sigma \sqrt{T-t} z+(T-t)\left(r-\sigma^{2} / 2\right)\right)\right)$ is the intrinsic value function of the option, which indicates the intrinsic value when the stock price is equal to $S \exp \left(\sigma \sqrt{T-t} z+(T-t)\left(r-\sigma^{2} / 2\right)\right)$.

In equation (1), when $S<X_{e}$ (out-of-the-money), there is no loss to abandon the options; when $S>X_{e}$ (in-the-money), the return is $S-X_{e}$ when exercising options. The integral result is derived by substituting (1) into (9); then the pricing model of the European call options for no-dividend paying stocks $V(S, t)$ is obtained by equation (10), that is, the famous B-S model:

$$
V(S, t)=S \times N\left(-d_{2}\right)-X_{e} \exp (-r(T-t)) N\left(-d_{1}\right) .
$$

We have

$$
\begin{aligned}
& d_{1}=\frac{\left(\ln \left(X_{e} / S\right)-\left(r-\sigma^{2} / 2\right)(T-t)\right)}{\sigma \sqrt{T-t}} \\
& d_{2}=\frac{\left(\ln \left(X_{e} / S\right)-\left(r+\sigma^{2} / 2\right)(T-t)\right)}{\sigma \sqrt{T-t}} .
\end{aligned}
$$

In equation $(10), N(d)$ is the probability distribution function of the standardized normal distribution. Note that $N\left(-d_{1}\right)$ is the probability of the future value of the underlying asset, which is conditioned on $S_{T}>X_{e}$, where $S_{T}$ is the price of the asset at the date of expiration. Moreover, $N\left(-d_{2}\right)$ is the probability that the option is exercised, which implies the call option is in money or $S_{T}<X_{e}$.

Different options have different intrinsic value functions. Substitute the specific intrinsic value function into the integral expression (9) for simplification; then the corresponding pricing model can be obtained.

5.2. Derivation of Real Option Pricing Model with the Sunk Cost in Upfront Investment. For real options which have sunk costs in upfront investment, the intrinsic value function of the option is given by (4). By substituting the intrinsic value function (4) into the integral expression (9) and simplifying the complex integral, the real option pricing model can be obtained. The specific mathematical derivation process is shown in the Appendix. The complete pricing model of real options with sunk costs is as follows:

$$
V(S, t)= \begin{cases}-\left(X_{e}-X_{\mathrm{res}}\right) \exp (-r(T-t)), & S<0, \\ S \times N\left(-z_{2}\right)-X_{e} \exp (-r(T-t))+X_{\mathrm{res}} \exp (-r(T-t)) N\left(z_{1}\right), & S>0,\end{cases}
$$

in which

$$
\begin{aligned}
& z_{1}=\frac{\left(\ln \left(X_{\mathrm{res}} / S\right)-\left(r-\sigma^{2} / 2\right)(T-t)\right)}{\sigma \sqrt{T-t}}, \\
& z_{2}=\frac{\left(\ln \left(X_{\mathrm{res}} / S\right)-\left(r+\sigma^{2} / 2\right)(T-t)\right)}{\sigma \sqrt{T-t}} .
\end{aligned}
$$

When $X_{\text {res }}=0$, we call it a complete sunk costs real option. We can see from the expressions of $z_{1}$ and $z_{2}$ in equation (12) that when $X_{\text {res }} \longrightarrow 0^{+}, \ln \left(X_{\text {res }} / S\right) \longrightarrow-\infty$; then $z_{1} \longrightarrow-\infty$ and $z_{2} \longrightarrow-\infty$, and thus $\lim _{X_{\text {res }} \longrightarrow 0^{+}} N\left(-z_{2}\right)=1$ and $\lim _{X_{\text {res }} \longrightarrow 0^{+}} N\left(z_{1}\right)=0$. Then, equation (12) becomes the following formula:

$$
V(S, t)= \begin{cases}-X_{e} \exp (-r(T-t)), & S \leq 0, \\ S-X_{e} \exp (-r(T-t)), & S>0 .\end{cases}
$$

At this point, the price of the real option has nothing to do with volatility $\sigma$ of the underlying asset price, which is an unexpected result to some extent. For risk-averse investors, the greater volatility $\sigma$ of the future is, the higher risk compensation the investors will demand, and the real option value seems to decrease with the increase of $\sigma$. However, this compensation mechanism is not reflected in the above pricing model, possibly because the effect of the asset price volatility is eliminated by offsetting the positive and negative option returns on two sides of the exercise price. When $S<X_{e} \exp (-r(T-t))$, the option value is less than 0 . When $S=X_{e} \exp (-r(T-t))$, the option value is equal to 0 , which is comparable to the situation where net present value is 0 . When $S>X_{e} \exp (-r(T-t))$, the real option value can be of positive values. In equation (12), if we want the option values to be nonnegative, then $S$ should satisfy the following inequality:

$$
S \geq\left(\frac{\left(X_{e}-X_{\text {res }} N\left(z_{1}\right)\right)}{N\left(-z_{2}\right)}\right) \exp (-r(T-t))
$$


When $X_{\text {res }}=X_{e}$, we call it the real option without sunk costs. From equation (12), we can get the corresponding option pricing model:

$$
\begin{aligned}
V(S, t)= & S \times N\left(-z_{2}\right)-X_{e} \exp (-r(T-t)) \\
& +X_{e} \exp (-r(T-t)) N\left(z_{1}\right) .
\end{aligned}
$$

According to the relation $N\left(-z_{1}\right)+N\left(z_{1}\right)=1$,

$$
V(S, t)=S \times N\left(-z_{2}\right)-X_{e} \exp (-r(T-t)) N\left(-z_{1}\right) .
$$

We have

$$
\begin{aligned}
& z_{1}=\frac{\left(\ln \left(X_{\mathrm{e}} / S\right)-\left(r-\sigma^{2} / 2\right)(T-t)\right)}{\sigma \sqrt{T-t}}, \\
& z_{2}=\frac{\left(\ln \left(X_{\mathrm{e}} / S\right)-\left(r+\sigma^{2} / 2\right)(T-t)\right)}{\sigma \sqrt{T-t}} .
\end{aligned}
$$

When $X_{\text {res }}=X_{e}$, the real option pricing model (17) was identical to the B-S model (10) of the European call option. This shows that using the B-S model of the financial option to evaluate the real option gives the correct result only when $X_{\text {res }}=X_{e}$.

When $S>0$, considering $X_{e}=X_{\text {res }}+X_{\text {sunk }}$, the pricing model of the real option with sunk costs can be written as the following form:

$$
V(S, t)=S \times N\left(-z_{2}\right)-X_{\text {res }} \exp (-r(T-t)) N\left(-z_{1}\right)-X_{\text {sunk }} \exp (-r(T-t)) .
$$

The first two items of the formula correspond to the B-S model when the strike price is $X_{\text {res, }}$, and the last item is the loss caused by sunk costs in the upfront investment.

\section{Characteristics of the Real Option Pricing Model Based on the Sunk Cost}

6.1. Real Option Value with the Sunk Cost Is an Incremental Function of the Upfront Investment Salvage Value. According to expression (9) of the B-S model, we can see that if the two intrinsic value functions $f_{1}(S)$ and $f_{2}(S)$ satisfy
$f_{1}(S) \leq f_{2}(S)$ and there is at least one point $S^{*}$ satisfying $f_{1}\left(S^{*}\right)<f_{2}\left(S^{*}\right)$, then the real option price determined by $f_{1}(S)$ must be less than the real option price determined by $f_{2}(S)$. Let us study the change characteristics of the real option value with sunk costs as the salvage value $X_{\text {res }}$ changes. Assuming that the other conditions remain unchanged, the parameters $X_{e}, \sigma^{2}, S, r, T$ of the two real options are all the same, but $X_{\text {res }}$ is different. Supposing that $X_{\text {res }}^{1}<X_{\text {res }}^{2} \leq X_{e}$, the corresponding intrinsic value function is as follows:

$$
f_{1}(S)=\left\{\begin{array}{ll}
-\left(X_{e}-X_{\mathrm{res}}^{1}\right), & S<X_{\mathrm{res}}^{1}, \\
S-X_{e}, & S \geq X_{\mathrm{res}}^{1},
\end{array} f_{2}(S)= \begin{cases}-\left(X_{e}-X_{\mathrm{res}}^{2}\right), & S<X_{\mathrm{res}}^{2} \\
S-X_{e}, & S \geq X_{\mathrm{res}}^{2}\end{cases}\right.
$$

Divide the interval $\left[0, X_{e}\right]$ into three segments: $\left[0, X_{\mathrm{res}}^{1}\right],\left[X_{\mathrm{res}}^{1}, X_{\mathrm{res}}^{2}\right]$, and $\left[X_{\mathrm{res}}^{2}, X_{e}\right]$. In $\left[X_{\mathrm{res}}^{2}, X_{e}\right]$, $f_{1}(S)=f_{2}(S)$. In $\left[0, X_{\text {res }}^{1}\right], \quad f_{1}(S)=-\left(X_{e}-X_{\text {res }}^{1}\right)$, $f_{2}(S)=-\left(X_{e}-X_{\text {res }}^{2}\right)$, since $\quad X_{\text {res }}^{1}<X_{\text {res }}^{2}$, so $X_{\text {res }}^{1}-X_{e}<X_{\text {res }}^{2}-X_{e}$; that is, $f_{1}(S)<f_{2}(S)$. In [ [ $\left.X_{\text {res }}^{1}, X_{\text {res }}^{2}\right]$,
$f_{1}(S)=S-X_{e}, f_{2}(S)=-\left(X_{e}-X_{\mathrm{res}}^{2}\right)$, since $S<X_{\mathrm{res}}^{2}$, so $S-X_{e}<X_{\text {res }}^{2}-X_{e}$; thus $f_{1}(S)<f_{2}(S)$. Thus, the option value corresponding to $f_{1}(S)$ is less than the option value corresponding to $f_{2}(S)$. The real option pricing model with sunk costs can be written in a form including parameter $X_{\text {res }}$.

$$
V\left(S, t, X_{\text {res }}\right)= \begin{cases}-\left(X_{e}-X_{\text {res }}\right) \exp (-r(T-t)), & S<0, \\ S \times N\left(-z_{2}\right)-X_{e} \exp (-r(T-t))+X_{\text {res }} \exp (-r(T-t)) N\left(z_{1}\right), & S>0 .\end{cases}
$$


TABLE 2: Results calculated by using financial options pricing model (10) and real option pricing model (12).

\begin{tabular}{|c|c|c|c|c|c|}
\hline \multirow{2}{*}{$\begin{array}{l}\text { The current price of asset } S \\
10\end{array}$} & \multirow{2}{*}{$\frac{\text { Financial call option }}{0.36}$} & \multicolumn{4}{|c|}{ Real options } \\
\hline & & -18.88 & -37.86 & -55.97 & -67.88 \\
\hline 20 & 2.16 & -16.35 & -34.07 & -49.78 & -57.88 \\
\hline 30 & 5.38 & -12.16 & -28.45 & -41.98 & -47.88 \\
\hline 40 & 9.75 & -6.77 & -21.68 & -33.38 & -37.88 \\
\hline 50 & 15.01 & -0.50 & -14.14 & -24.34 & -27.88 \\
\hline 60 & 20.99 & 6.43 & -6.08 & -15.03 & -17.88 \\
\hline 70 & 27.53 & 13.86 & 2.38 & -5.54 & -7.88 \\
\hline 80 & 34.53 & 21.68 & 11.11 & 4.07 & 2.12 \\
\hline 90 & 41.90 & 29.83 & 20.07 & 13.77 & 12.12 \\
\hline 100 & 49.60 & 38.22 & 29.19 & 23.52 & 22.12 \\
\hline 200 & 136.26 & 129.60 & 124.93 & 122.54 & 122.12 \\
\hline 300 & 230.64 & 226.33 & 223.55 & 222.30 & 222.12 \\
\hline 400 & 327.74 & 324.76 & 322.95 & 322.21 & 322.12 \\
\hline 500 & 426.05 & 423.89 & 422.65 & 422.17 & 422.12 \\
\hline
\end{tabular}

Note: $X_{e}=10^{8}, T=5, \sigma=0.5$, and $r=0.05$. Columns $3,4,5$, and 6 correspond to $X_{\text {res }}$ values of $0.75 * 10^{8}, 0.5 * 10^{8}, 0.25 * 10^{8}$, and 0 , respectively. The magnitude of the data in the table is $10^{6}$.

The result proved above can be expressed as

$$
\frac{\partial V\left(S, t, X_{\text {res }}\right)}{\partial X_{\text {res }}}>0 .
$$

The real option value with the sunk cost is the increasing function of the upfront investment salvage value $X_{\text {res }}$.

\subsection{Real Option Value with Salvage Value Could Be More} Accurately Estimated. As we can see from the intrinsic value function (1) of a European call option and the intrinsic value function (4) of a real option with salvage value, if $X_{\text {res }}<X_{e}$, when $S \geq X_{e}$, the two intrinsic value functions are the same. When $S<X_{e}$, the value of the intrinsic value function of the financial options is 0 , and the value of the intrinsic value function of real options with salvage value is negative, so the real option value calculated by the B-S model for the European financial call option must be overvalued. Notably, in the fields of mineral resources development, project investment, and high-tech research and development, the sunk cost accounts for a large proportion of upfront investment in most cases. For real options, when $X_{\text {res }}$ has a small value and $S$ is far less than $X_{e}$, the intrinsic value of real options could be negative. In this case, it is wrong to directly apply the B-S model.

Table 2 shows some results calculated by using financial option pricing model (10) and real option pricing model (12). We set the salvage value in upfront investment at different levels. The calculation results show the difference between the value of the real option and financial option at different price intervals. If the salvage value in upfront investment is very small and the current asset price is also small, then the option value is a negative number with large absolute value. When the current asset price is far more than the exercise price, the option values calculated by the two option pricing models are very close.

For the production and operation of a project, investors are most concerned about the return and often require a project to have the maximum positive option value. For the new technology research and development of real options, not only are investors concerned about the future return, but also they do not want to be surpassed by competitors. The value of such options is generally negative, and it is the cost that investors incur for acquiring new technology. In this case, investors need to assess whether it is worthwhile to pay the cost, which is equivalent to the option value for the new technology.

\section{Conclusion and Discussion}

This paper discusses the essential differences between real options and financial options, including the sunk cost feature in the real option's exercise price. Based on the sunk cost feature in the real option's exercise price, the conditions of exercising or abandoning real options are given. On this basis, the sunk cost characteristic is introduced into the intrinsic value function of real options, and a new real option pricing model is developed with the help of the integral formulation of the solution of the Black-Scholes differential equation. Finally, the pricing model is analyzed, and some characteristics of the model are identified.

We find that the exercise price of the real option, contrary to the strike price of the financial options, which is agreed upon at the time of writing the contract, is set not at the time of the investor's upfront capital outlays but after the start of production. This implies that the return is determined only after production begins. Both the gestation of investment to the production stage and the actual production are time-dependent and are stochastic processes. We consider time as the essence in the real options in the sense of the time it takes for the initial investment to be fully completed and the time it takes for production to begin so that the real investment project's value could be determined. Furthermore, this paper indicates that the intrinsic value of the real option is negative when the market price of the option is lower than the exercise price. Only when the market price of the option is higher than the exercise price could its intrinsic value function show the same form as that of the financial option. Unlike financial options, the real option will be exercised when the market price of the real 
option is greater than the upfront investment salvage value, while the option will be abandoned when the market price of the real option is less than the upfront investment salvage value.

The general form of the real options corresponds to the financial call option, while the financial put option corresponds to the special forms of real options such as the contract real options. This paper only discusses the general form of real option pricing model; the contract real options and the expansion real option pricing model are the subjects of our ongoing research and the results will be presented in the future.

\section{Appendix}

For real options which have sunk costs in upfront investment, the intrinsic value function of the option is

$$
f(u)= \begin{cases}-\left(X_{e}-X_{\text {res }}\right), & u<X_{\text {res }}, \\ u-X_{e}, & u \geq X_{\text {res }} .\end{cases}
$$

The Black-Scholes' integral expression of the solution of the partial differential equation is

$$
V(S, t)=\left(\frac{\exp (-r(T-t))}{\sqrt{2 \pi}}\right) \int_{-\infty}^{+\infty} f\left(S \exp \left(\sigma \sqrt{T-t} z+(T-t)\left(\frac{r-\sigma^{2}}{2}\right)\right)\right) \exp \left(\frac{-z^{2}}{2}\right) \mathrm{d} z
$$

In the above integral expression, there is

$$
u=S \exp \left(\sigma \sqrt{T-t} z+\left(\frac{r-\sigma^{2}}{2}\right)(T-t)\right) .
$$

Since $\exp (x)>0$, the signs of $u$ and $S$ are the same. Study the situation in which $S>0$ first. There is

$$
S \exp \left(\sigma \sqrt{T-t} z+\left(\frac{r-\sigma^{2}}{2}\right)(T-t)\right)>0 .
$$

Because of $S>0$, there cannot be a situation in which $u<0$, and so $z \in(-\infty,+\infty)$. The intrinsic value of the option is represented by a segment function, and the two intervals are $0<u<X_{\text {res }}$ and $u>X_{\text {res }}$. When $u<X_{\text {res }}$,

$$
S \exp \left(\sigma \sqrt{T-t} z+\left(\frac{r-\sigma^{2}}{2}\right)(T-t)\right)<X_{\text {res }}
$$

Take the logarithm on both sides and get

When $u>X_{\text {res }}$,

$$
S \exp \left(\sigma \sqrt{T-t} z+\left(r-\sigma^{2} / 2\right)(T-t)\right)>X_{\text {res }} \text {. }
$$

Take the logarithm on both sides and get

$$
z>\frac{\left(\ln \left(X_{\text {res }} / S\right)-\left(r-\sigma^{2} / 2\right)(T-t)\right)}{\sigma \sqrt{T-t}} .
$$

Mark as

$$
z_{1}=\frac{\left(\ln \left(X_{\mathrm{res}} / S\right)-\left(r-\sigma^{2} / 2\right)(T-t)\right)}{\sigma \sqrt{T-t}} .
$$

By substitution into (A.2), the intrinsic value integral expression of the real option with sunk costs can be obtained as follows:

$$
V(S, t)=\left(\frac{\exp (-r(T-t))}{\sqrt{2 \pi}}\right)\left(\int_{-\infty}^{z_{1}}-\left(X_{e}-X_{\mathrm{res}}\right) \exp \left(\frac{-z^{2}}{2}\right) \mathrm{d} z+\int_{z_{1}}^{-\infty}\left(S \exp \left(\sigma \sqrt{T-t} z+\left(\frac{r-\sigma^{2}}{2}\right)(T-t)\right)-X_{e}\right) \exp \left(\frac{-z^{2}}{2}\right) \mathrm{d} z\right)
$$

Mark as

$$
\begin{aligned}
& V_{1}=\left(\frac{\exp (-r(T-t))}{\sqrt{2 \pi}}\right) \int_{z_{1}}^{-\infty}\left(S \exp \left(\sigma \sqrt{T-t} z+\left(\frac{r-\sigma^{2}}{2}\right)(T-t)\right)-X_{e}\right) \exp \left(\frac{-z^{2}}{2}\right) \mathrm{d} z . \\
& V_{2}=\left(\frac{\exp (-r(T-t))}{\sqrt{2 \pi}}\right) \int_{-\infty}^{z_{1}}-\left(X_{e}-X_{\text {res }}\right) \exp \left(\frac{-z^{2}}{2}\right) \mathrm{d} z .
\end{aligned}
$$


Then

$$
V_{1}=\left(\frac{\exp (-r(T-t))}{\sqrt{2 \pi}}\right) \int_{z_{1}}^{-\infty}\left(S \exp \left(\left(\frac{-1}{2}\right) z^{2}+\sigma \sqrt{T-t} z+\left(\frac{r-\sigma^{2}}{2}\right)(T-t)\right)-X_{e} \exp \left(\frac{-z^{2}}{2}\right)\right) \mathrm{d} z
$$

For the expression in the integrand function in $V_{1}$,

We did the following rearrangements:

$$
\left(\frac{-1}{2}\right) z^{2}+\sigma \sqrt{T-t} z+\left(\frac{r-\sigma^{2}}{2}\right)(T-t)
$$

$$
\begin{aligned}
& \left(\frac{-1}{2}\right) z^{2}+\sigma \sqrt{T-t} z+\left(\frac{r-\sigma^{2}}{2}\right)(T-t) \\
& =\left(\frac{-1}{2}\right) z^{2}+\sigma \sqrt{T-t} z+r(T-t)-\left(\frac{\sigma^{2}}{2}\right)(T-t) \\
& =\left(\frac{-1}{2}\right)\left[z^{2}-2 \sigma \sqrt{T-t} z+\sigma^{2}(T-t)\right]+r(T-t) \\
& =\left(\frac{-1}{2}\right)(z-\sigma \sqrt{T-t})^{2}+r(T-t)
\end{aligned}
$$

Solve the first part:

$$
V_{1}=\left(\frac{\exp (-r(T-t))}{\sqrt{2 \pi}}\right) \int_{z_{1}}^{-\infty}\left(S \exp \left(\left(\frac{-1}{2}\right) z^{2}+\sigma \sqrt{T-t} z+\left(\frac{r-\sigma^{2}}{2}\right)(T-t)\right)-X_{e} \exp \left(\frac{-z^{2}}{2}\right)\right) \mathrm{d} z
$$

Rearrange the above integrations:

$$
\begin{aligned}
V_{1} & =\left(\frac{\exp (-r(T-t))}{\sqrt{2 \pi}}\right) \int_{z_{1}}^{+\infty}\left(S \exp \left(\left(\frac{-1}{2}\right) z^{2}+\sigma \sqrt{T-t} z+\left(\frac{r-\sigma^{2}}{2}\right)(T-t)\right)-X_{e} \exp \left(\frac{-z^{2}}{2}\right)\right) \mathrm{d} z \\
& =\left(\frac{\exp (-r(T-t))}{\sqrt{2 \pi}}\right) S \exp (-r(T-t)) \int_{z_{1}}^{+\infty} \exp \left(\frac{-1}{2}\right)(z-\sigma \sqrt{T-t})^{2} \mathrm{~d} z-X_{e} \int_{z_{1}}^{+\infty} \exp \left(\frac{-z^{2}}{2}\right) \mathrm{d} z
\end{aligned}
$$

Using variable substitution, make $y=z-\sigma \sqrt{T-t}, z_{2}=z_{1}-\sigma \sqrt{T-t}, \mathrm{~d} y=\mathrm{d} z$; then the first item of the above integral is

$$
\left(\frac{1}{\sqrt{2 \pi}}\right) \int_{z_{2}}^{+\infty} S \exp \left(\frac{-y^{2}}{2}\right) \mathrm{d} y=S \times\left(1-N\left(z_{2}\right)\right)=S \times N\left(-z_{2}\right)
$$


The second item of the above integral is

$$
\begin{aligned}
& \left(\frac{\exp (-r(T-t))}{\sqrt{2 \pi}}\right) \int_{z_{1}}^{+\infty}-X_{e} \exp \left(\frac{-z^{2}}{2}\right) \mathrm{d} z \\
& \quad=-X_{e} \exp (-r(T-t))\left(1-N\left(z_{1}\right)\right)=-X_{e} \exp (-r(T-t)) N\left(-z_{1}\right) .
\end{aligned}
$$

Combine the results of the above two parts:

Solve the second part:

$$
V_{1}=S \times N\left(-z_{2}\right)-X_{e} \exp (-r(T-t)) N\left(-z_{1}\right) \text {. }
$$

$$
\begin{aligned}
V_{2} & =\left(\frac{\exp (-r(T-t))}{\sqrt{2 \pi}}\right) \int_{-\infty}^{z_{1}}\left(X_{\text {res }}-X_{e}\right) \exp \left(\frac{-z^{2}}{2}\right) \mathrm{d} z \\
& =\exp (-r(T-t))\left(X_{\text {res }}-X_{e}\right)\left(\frac{1}{\sqrt{2 \pi}}\right) \int_{-\infty}^{z_{1}} \exp \left(\frac{-z^{2}}{2}\right) \mathrm{d} z \\
& =\exp (-r(T-t))\left(X_{\text {res }}-X_{e}\right) N\left(z_{1}\right) .
\end{aligned}
$$

Combine $V_{1}$ and $V_{2}$, and we can get

$$
\begin{aligned}
V(S, t) & =V_{1}+V_{2} \\
& =S \times N\left(-z_{2}\right)-X_{e} \exp (-r(T-t)) N\left(-z_{1}\right)-\exp (-r(T-t))\left(X_{e}-X_{\text {res }}\right) N\left(z_{1}\right) .
\end{aligned}
$$

Note that $N\left(-z_{1}\right)+N\left(z_{1}\right)=1$. Substitute $1-N\left(z_{1}\right)$ for $N\left(-z_{1}\right)$ in the upper equation. After rearrangements, the real option pricing model with the sunk cost is obtained when $S>0$.

$$
V=S \times N\left(-z_{2}\right)-X_{e} \exp (-r(T-t))+X_{\text {res }} \exp (-r(T-t)) N\left(z_{1}\right) .
$$

We have

$$
\begin{aligned}
& z_{1}=\frac{\left(\ln \left(X_{\mathrm{res}} / S\right)-\left(r-\sigma^{2} / 2\right)(T-t)\right)}{\sigma \sqrt{T-t}}, \\
& z_{2}=\frac{\left(\ln \left(X_{\mathrm{res}} / S\right)-\left(r+\sigma^{2} / 2\right)(T-t)\right)}{\sigma \sqrt{T-t}} .
\end{aligned}
$$

Study the situation in which $S<0$. According to equation (A.1), the intrinsic value function takes a constant value $-\left(X_{e}-X_{\text {res }}\right)$, and then

$$
u=S \exp \left(\sigma \sqrt{T-t} z+\left(\frac{r-\sigma^{2}}{2}\right)(T-t)\right)<0 .
$$

The integration range of $z$ is $(-\infty,+\infty)$; and substitute it into the integration formula (A.2); then

$$
\begin{aligned}
V(S, t) & =\left(\frac{\exp (-r(T-t))}{\sqrt{2 \pi}}\right) \int_{-\infty}^{+\infty}\left(X_{\text {res }}-X_{e}\right) \exp \left(\frac{-z^{2}}{2}\right) \mathrm{d} z \\
& =\exp (-r(T-t))\left(X_{\text {res }}-X_{e}\right)\left(\frac{1}{\sqrt{2 \pi}}\right) \int_{-\infty}^{+\infty} \exp \left(\frac{-z^{2}}{2}\right) \mathrm{d} z \\
& =-\left(X_{e}-X_{\text {res }}\right) \exp (-r(T-t)) .
\end{aligned}
$$

A complete pricing model of real options with sunk costs is obtained: 


$$
V(S, t)= \begin{cases}-\left(X_{e}-X_{\text {res }}\right) \exp (-r(T-t)), & S<0, \\ S \times N\left(-z_{2}\right)-X_{e} \exp (-r(T-t))+X_{\text {res }} \exp (-r(T-t)) N\left(z_{1}\right), & S>0,\end{cases}
$$

in which

$$
\begin{aligned}
& z_{1}=\frac{\left(\ln \left(X_{\mathrm{res}} / S\right)-\left(r-\sigma^{2} / 2\right)(T-t)\right)}{\sigma \sqrt{T-t}}, \\
& z_{2}=\frac{\left(\ln \left(X_{\mathrm{res}} / S\right)-\left(r+\sigma^{2} / 2\right)(T-t)\right)}{\sigma \sqrt{T-t}} .
\end{aligned}
$$

\section{Data Availability}

Simulation data and variable parameter settings are available within the manuscript.

\section{Conflicts of Interest}

The authors declare that there are no conflicts of interest regarding the publication of this article.

\section{Acknowledgments}

This work was supported by the National Natural Science Foundation of China (Grant no. 71773024), the Natural Science Foundation of Heilongjiang Province of China (Grant no. G2018006), and the Heilongjiang Postdoctoral Scientific Research Developmental Fund (Grant no. LBH-Q18064).

\section{References}

[1] S. C. Myers, "Determinants of corporate borrowing," Journal of Financial Economics, vol. 5, no. 2, pp. 147-175, 1977.

[2] J. Alleman, Lenos Trigeorgis, Real Options: Management Flexibility and Strategy in Resource Allocation, MIT Press, Cambridge, MA, USA, 1999, https://pdfs.semanticscholar. org/9248/6ee35f15e64fa85713bba9da8060ea82a3ff.pdf.

[3] J. S. Busby and C. G. C. Pitts, "Real options in practice: an exploratory survey of how finance officers deal with flexibility in capital appraisal," Management Accounting Research, vol. 8, no. 2, pp. 169-186, 1997.

[4] J. O’Brien and T. Folta, "Sunk costs, uncertainty and market exit: a real options perspective," Industrial and Corporate Change, vol. 18, no. 5, pp. 807-833, 2009.

[5] J. Reuer and W. Tong, "How do real options matter? Empirical research on strategic investments and firm performance," Advances in Strategic Management, vol. 24, pp. 145-173, 2007.

[6] A. Dixit, "Entry and exit decisions under uncertainty," Journal of Political Economy, vol. 97, no. 3, pp. 620-638, 1989.

[7] A. Dixit, "Investment and hysteresis," The Journal of Economic Perspectives, vol. 6, no. 1, pp. 107-132, 1992.

[8] R. McDonald and D. Siegel, "The value of waiting to Invest," The Quarterly Journal of Economics, vol. 101, no. 4, pp. 707-727, 1986.

[9] A. Milne and A. E. Whalley, "Time to build, option value and investment decisions: a comment," Journal of Financial Economics, vol. 56, no. 2, pp. 325-332, 2000.

[10] A. Baranov and E. Muzyko, "Valuation of compound real options for investments in innovative projects in pharmaceutical industry," Procedia Economics and Finance, vol. 27, pp. 116-125, 2015.
[11] G. Martin-Barrera, C. Zamora-Ramirez, and J. M. GonzalezGonzalez, "Application of real options valuation for analysing the impact of public R\&D financing on renewable energy projects: a company's perspective," Renewable and Sustainable Energy Reviews, vol. 63, pp. 292-301, 2016.

[12] H. Weeds, "Strategic delay in a real options model of R\&D competition," The Review of Economic Studies, vol. 69, no. 3, pp. 729-747, 2002.

[13] D. Barbosa, V. M. Carvalho, and P. J. Pereira, "Public stimulus for private investment: an extended real options model," Economic Modelling, vol. 52, pp. 742-748, 2016.

[14] C. M. Regan, B. A. Bryan, J. D. Connor et al., "Real options analysis for land use management: methods, application, and implications for policy," Journal of Environmental Management, vol. 161, pp. 144-152, 2015.

[15] S. Arif, N. Marshall, and T. L. Yohn, "Understanding the relation between accruals and volatility: a real options-based investment approach," Journal of Accounting and Economics, vol. 62, no. 1, pp. 65-86, 2016.

[16] M. Odening, O. Musshoff, and A. Balmann, "Investment decisions in hog finishing: an application of the real options approach," Agricultural Economics, vol. 32, no. 1, pp. 47-60, 2015.

[17] E. R. Arzac, Valuation of Mergers, Buyouts, and Restructuring, Wiley \& Sons, Hoboken, NJ, USA, 2nd edition, 2005.

[18] A. Soofi and Y. Zhang, Global Mergers and Acquisitions: Combining Companies across Borders, Business Expert Press, New York, NY, USA, 2nd edition, 2018.

[19] Z. Zmeškal, "Generalised soft binomial American real option pricing model (fuzzy-stochastic approach)," European Journal of Operational Research, vol. 207, no. 2, pp. 1096-1103, 2010.

[20] A. M. Heng, Q. Chen, and Y. S. Tan, "Fuzzy optimization of option pricing model and its application in land expropriation," Journal of Applied Mathematics, vol. 2014, Article ID 635898, 7 pages, 2014.

[21] M. Zubrii, A. Mazur, and V. Kobets, "Forecasting real option price model by means of evolutionary and genetic algorithms," Lecture Notes in Mechanical Engineering, Springer, Berlin, Germany, pp. 214-224, 2019.

[22] K. Coucke, E. Pennings, and L. Sleuwaegen, "Employee layoff under different modes of restructuring: exit, downsizing or relocation," Industrial and Corporate Change, vol. 16, no. 2, pp. 161-182, 2007.

[23] E. Bartelsman, S. Scarpetta, and F. Schivardi, "Comparative analysis of firm demographics and survival: evidence from micro-level sources in OECD countries," Industrial and Corporate Change, vol. 14, no. 3, pp. 365-391, 2005.

[24] E. Santarelli and M. Vivarelli, "Entrepreneurship and the process of firms' entry, survival and growth," Industrial and Corporate Change, vol. 16, no. 3, pp. 455-488, 2007. 